\title{
Exchange of molecular and cellular information: a hybrid model that integrates stem cell divisions and key regulatory interactions
}

Lisa Van den Broeck ${ }^{1}$, Ryan J. Spurney ${ }^{2}$, Adam P. Fisher ${ }^{1}$, Michael Schwartz ${ }^{1}$, Natalie M. Clark ${ }^{3}$, Thomas

T. Nguyen ${ }^{1}$, Imani Madison ${ }^{1}$, Mariah Gobble ${ }^{1}$, Terri Long $^{1}$, Rosangela Sozzani ${ }^{1 *}$

${ }^{1}$ Plant and Microbial Biology Department, North Carolina State University, Raleigh, NC 27695

${ }^{2}$ Electrical and Computer Engineering Department, North Carolina State University, Raleigh, NC 27695

${ }^{3}$ Department of Plant Pathology and Microbiology, lowa State University, Ames, lowa 50010

*Corresponding author: ross_sozzani@ncsu.edu

ORCIDs:

Lisa Van den Broeck (0000-0003-0226-0757)

Natalie M. Clark (0000-0003-0988-321X)

Rosangela Sozzani (0000-0003-3316-2367)

Terri Long (0000-0001-7846-0195)

Michael Schwartz (0000-0002-5434-6248)

Ryan Spurney (0000-0001-9915-3370) 
bioRxiv preprint doi: https://doi org/10.1101/202011.30.404426; this version posted December 1,2020. The copyright holder for this preprint (which was not certified by peer review) is the author/funder, who has granted bioRxiv a license to display the preprint in perpetuity. It is made available under aCC-BY 4.0 International license.

\section{Abstract}

Stem cells give rise to the entirety of cells within an organ. Maintaining stem cell identity and coordinately regulating stem cell divisions is crucial for proper development. In plants, mobile proteins, such as WOX5 and SHR, regulate divisions in the root stem cell niche (SCN). However, how these proteins coordinately function to establish systemic behavior is not well understood. We propose a non-cell autonomous role for WOX5 in the CEI and identify a regulator, AN3/GIF1, that coordinates CEI divisions. Here we show with a multiscale hybrid model integrating ODEs and agent-based modeling that QC and CEI divisions have different dynamics. Specifically, by combining continuous models to describe regulatory networks and agent-based rules, we model systemic behavior, which led us to predict cell-type-specific expression dynamics of SHR, SCR, WOX5, AN3, and CYCD6;1, and experimentally validate CEI cell divisions. Conclusively, our results show an interdependency between CEI and QC divisions.

\section{Thumbnail image}

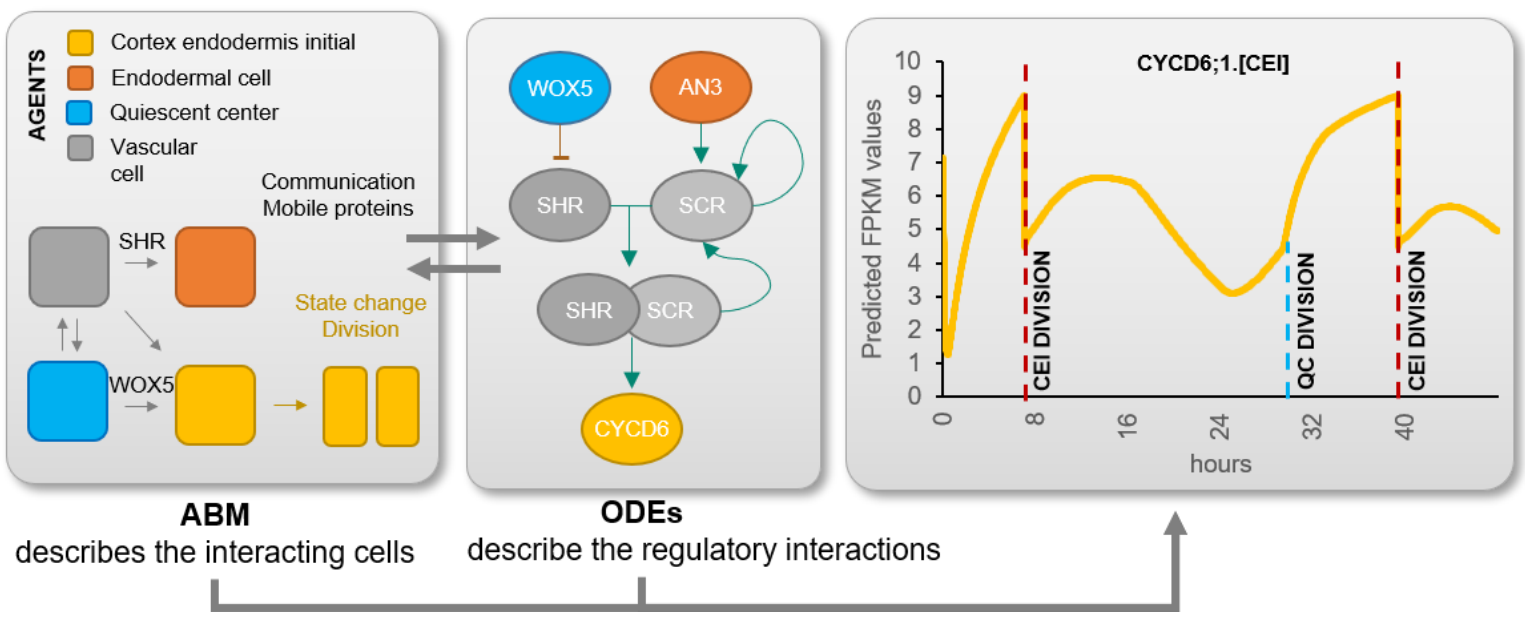

\section{Keywords}

Root stem cell niche, AN3, WOX5, cortex endodermal initial divisions, agent-based modeling, ordinary differential equations, hybrid multiscale modeling 
bioRxiv preprint doi: https://doi.org/10.1101/2020.11.30.404426; this version posted December 1, 2020. The copyright holder for this preprint (which was not certified by peer review) is the author/funder, who has granted bioRxiv a license to display the preprint in perpetuity. It is made available under aCC-BY 4.0 International license.

\section{Introduction}

Stem cells divide to regenerate themselves and to generate all of the cell- and tissue-types in a multicellular organism, such as plants. The continued ability to sustain stem cells within their microenvironment, the stem cell niche ( $\mathrm{SCN})$, is an important developmental characteristic that ensures proper tissue growth. The Arabidopsis thaliana root SCN contains four stem cell populations, the columella stem cells (CSCs), the cortex endodermis initial (CEI) cells, the vascular initial cells, and the epidermal/lateral root cap initials, which form the entire root as a result of consecutive cell divisions (Dinneny \& Benfey, 2008; Fisher \& Sozzani, 2016). The different populations of stem cells are maintained by the quiescent center $(Q C)$ through the generation of short-range signals that repress cell differentiation (Clark, Fisher, et al., 2020; Pi et al., 2015; van den Berg et al., 1997). A known QCderived signal is the homeobox transcription factor (TF) WUSCHEL-RELATED HOMEOBOX 5 (WOX5), which is specifically expressed in the QC and represses the differentiation of the CSCs (Petricka et al., 2012; Sarkar et al., 2007). Specifically, non-cell-autonomous WOX5 maintenance of CSCs takes place through the repression of the differentiation factor CYCLING DOF FACTOR 4 (CDF4) (Pi et al., 2015). wox5-1 mutants have increased QC divisions in roots and a decreased number of columella cell layers (Forzani et al., 2014). In the QC cells, WOX5 controls divisions by restricting CYCD3;3 expression (Forzani et al., 2014). Although the regulatory modules within the CSCs and QC are well characterized (Forzani et al., 2014; Stahl et al., 2013), the molecular mechanisms by which WOX5 promotes stem cell fate of CEIs remains unknown.

Several proteins have been shown to positively regulate WOX5, such as ANGUSTIFOLIA (AN3) / GRFINTERACTING FACTOR 1 (GIF1). AN3 is expressed in the root meristem with a high peak in expression in the SCN and QC and plays a role in maintaining QC identity (Ercoli et al., 2018). However, whether AN3 function is dependent on WOX5 and whether AN3 has a regulatory role outside the QC in the SCN is not understood. Additionally, AN3 was shown to regulate the expression of SCARECROW (SCR) (Ercoli et al., 2018), which along with SHORT-ROOT (SHR) regulates the expression of the D-type Cyclin CYCLIND6;1 (CYCD6;1) to control the CEI divisions to generate the cortical and endodermal tissue layers (Cruz-Ramírez et al., 2012; Gallagher \& Benfey, 2009; Long et al., 2015; Nakajima et al., 2001; Sozzani et al., 2010). Specifically, SHR moves from the vasculature to the CEI, where it forms a complex with SCR to transcriptionally regulate CYCD6;1.

The regulatory interactions between the different cell types of the root SCN are complex and nonintuitive and computational tools are essential to understanding systemic behavior. Developmental processes such as auxin flow within the root and lateral shoot branching have been mathematically modeled to better understand and predict system-level behavior (Canher et al., 2020; Prusinkiewicz et al., 2009). Some models implement different scales of the system to simulate, understand, and predict 
bioRxiv preprint doi: https://doi.org/10.1101/20201130.404426; this version posted December 1, 2020. The copyright holder for this preprint (which was not certified by peer review) is the author/funder, who has granted bioRxiv a license to display the preprint in perpetuity. It is made available under aCC-BY 4.0 International license.

system-level behavior as a whole. For example, a mathematical model that simulates and predicts the induction of shoot branching during plant development included on a molecular scale auxin flux across metamers (i.e. smaller segments of the stem) and on an organ scale the formation of metamers of the stem and lateral branches (Prusinkiewicz et al., 2009). Modeling systems and allowing exchange of information across different scales can also be achieved by combining agent-based models (ABM) with continuous models, such as ordinary differential equations (ODEs) or partial differential equations (Cilfone et al., 2015). ABMs consist of autonomous "agents" that dynamically interact and show responsive behavior through a set of simple rules. $A B M s$ have, for example, been used to simulate plant-herbivore interactions (Radny \& Meyer, 2018). However, within the molecular plant biology field, these models are not widely used, despite their capacity to capture system-level behavior. On the other hand, continuous models such as ODEs have been applied to infer gene regulatory networks (Krouk et al., 2010; Yao et al., 2011) and predict dynamic gene expression patterns (Clark, Fisher, et al., 2020). These models are computationally intensive and lack the capability to capture system-level behavior but can model complex dynamic responses over time. Hybrid models are created when, for example, continuous models are used within a discrete $A B M$ to describe a part of the system. These hybrid models are usually multiscale models, given that the continuous models often describe a dynamical response on a different spatiotemporal scale than the ABM (Cilfone et al., 2015).

In this study, we combine cell-type-specific gene expression data and experimental data with network inference and parametric models to better understand how WOX5, AN3, SCR, and SHR coordinately regulate CEI stem cell divisions. We transcriptionally profiled CEI cells in wild-type and wox5-1 roots, as well as QC cells and non-stem cells. We found that AN3 was among the most CEl-enriched genes. Additionally, the loss-of-function of wox 5 or an 3 resulted in an extended expression pattern of the CEI stem cell marker CYCD6; 1 into the cortex and endodermal cells. We built an ODE and agent-based hybrid model linking cell behavior, specifically cell division, to gene expression dynamics represented by ODEs of WOX5, AN3, SCR, SHR and CYCD6;1. Our hybrid model allowed for the exchange of information between a cellular scale (i.e. division of stem cells) and a molecular scale (i.e. regulatory interactions at single cell level). In the hybrid model, the mobile proteins, WOX5 and SHR, regulated the expression of downstream proteins non-cell autonomously in specific cell-types. The communication between cell types and dynamic expression patterns modeled experimentally validated temporal stem cell divisions. 


\section{Results}

\section{WOX5 regulates CEI-specific genes}

The functional role of WOX5 in the QC and CSC has been extensively reported while its role in stem cell populations remains largely unknown. WOX5 is specifically expressed in the QC cells, however, the protein moves to the CSCs and the vasculature initials and has been shown to have a non-cell autonomous role in these cells (Clark et al., 2019; Pi et al., 2015). To determine whether WOX5 is also able to move from the QC cells to the QC-neighboring CEI cells and regulate downstream targets, we used scanning fluorescence correlation spectroscopy (scanning FCS). Five-day-old wox5xpWOX5:WOX5-GFP plants were analyzed with scanning FCS to evaluate the directional movement of WOX5 protein between these two cell-types. Line scans were taken over time from a region spanning the CEI and adjacent QC (Fig 1A). This analysis resulted in a quantitative assessment of movement and allowed us to calculate the movement index (MI). We found that WOX5 moved bidirectionally between the $Q C$ and the $\mathrm{CEI}(\mathrm{MI}=0.90 \pm 0.04$ from $Q \mathrm{C}$ to $\mathrm{CEI}, \mathrm{MI}=0.83 \pm 0.05$ from CEI to $Q C, n=20$ ) (Supplemental Table 1). As a comparison, within the SCN, free GFP and immobile 3xGFP have a moving index of $\sim 0.7$ and $\sim 0.25$, respectively (Clark et al., 2016).

To explore the potential functional role of WOX5 in CEI, we examined the expression pattern of the CEI-marker pCYCD6;1:GFP in wox5. The marker showed an expression pattern that extended into the cortex and endodermal cells (Fig 1B,C). This expanded expression of CYCD6;1 suggests that the 4 to 5 cells proximal of the CEI, referred hereafter as CEI-like cells, have gained stem cell-like characteristics and also indicates that WOX5 controls CYCD6;1 expression to the CEI (Fig 1B). We then explored the role of WOX5 in limiting CYCD6;1 expression and, thus, controlling CEI divisions. To this end, we quantified the number of undivided and divided CEI cells in 4-, 5-, and 6-day-old wox5 and wild-type roots. This quantification showed that wox5xpCYCD6;1:GUS-GFP roots had an increase of $23.43 \%$ and 25.33\% ( $p=0.0495$, Wilcoxon test) divided CEI cells compared to the wild type (WT) at 4 and 6 days, respectively (Fig 1D). Taken together, these results support a functional non-cell autonomous role for WOX5 in the CEI. 

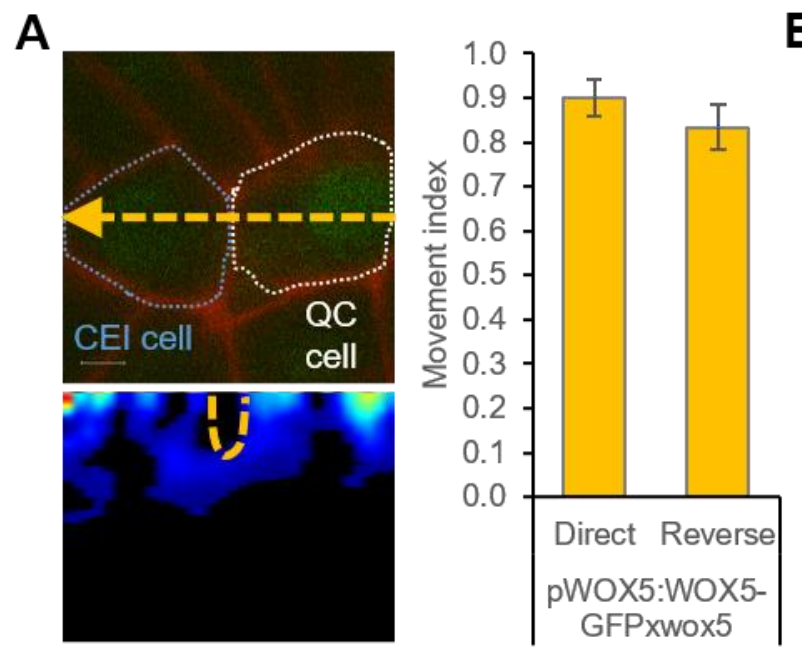

B
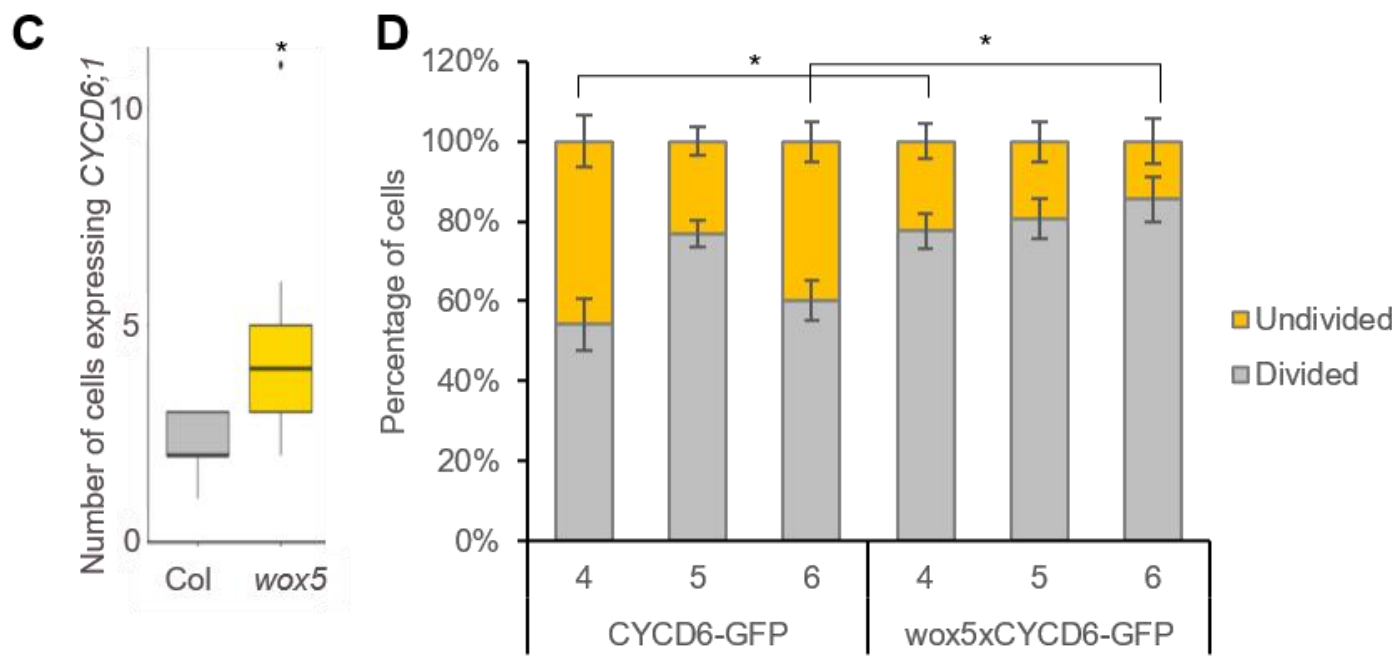

Figure 1 - Characterization of WOX5 in the CEI. (A) (Top - left) Confocal image of a region in the wox5xpWOX5:WOX5-GFP root spanning the quiescent center (QC) and cortex endodermis initial (CEI) used for PCF. The location and direction of the line scan (orange dashed line) is marked onto the image. (Bottom - left) pCF carpet image of the top image. Orange, dashed regions represent an arch in the PCF carpet, which indicates movement. (Right) Movement index of wox5xpWOX5:WOX5GFP between the QC and CEI. (B) Confocal image wox5xpCYCD6;1:GUS-GFP roots. (C) The number of CEI and CEI-like cells expressing pCYCD6;1:GUS-GFP. (D) Percentage of divided and undivided CEI cells in pCYCD6;1:GUS-GFP and wox5xpCYCD6;1:GUS-GFP roots. Data are presented as mean \pm SEM. ${ }^{*}=p<0.05$ (C,D: Wilcoxon Chi-square test). Error bars represent SEM.

\section{Network inference and node importance analysis to identify functional candidates}

To unravel the transcriptional events regulating the extended expression pattern of $C Y C D 6 ; 1$ in the wox5 mutant background, a transcriptome analysis was performed on FACS-sorted GFP positive cells from pCYCD6;1:GUS-GFP, wox5xpCYCD6;1:GUS-GFP, and pWOX5:GFP, and the meristematic cells from pWOX5-GFP that do not express the marker (referred to as non-stem cells) (Supplemental Table 2). Compared to the cells not expressing the pWOX5-GFP marker, 163 genes were differentially expressed (FDR $<0.05$ ) in wild-type CEI cells and 213 genes in the CEI and CEI-like cells from the wox5 mutant. In total, the union of these two analyses identified 330 DEGs in CEI and CEI-like cells, of which 159 DEGs 
bioRxiv preprint doi: https://doi.org/10.1101/20201130.404426; this version posted December 1, 2020. The copyright holder for this preprint (which was not certified by peer review) is the author/funder, who has granted bioRxiv a license to display the preprint in perpetuity. It is made available under aCC-BY 4.0 International license.

108 (48.18\%) have previously been shown to be expressed in the SCN and 53 genes were enriched in the 109 CEI (Clark et al., 2019). We hypothesized that the regulatory genes underlying CYCD6;1 expression should be differentially expressed in the CEl cells (CYCD6;1 expressing cells) of the wild-type and wox5 roots and thus focused on the genes overlapping between these two sets of DEGs (Fig 2A). In total, 46 genes overlapped between the CEI and CEI-like cells, which equals an enrichment of $35.8(p<4.431 \mathrm{e}-$ 59, Exact hypergeometric probability). To identify key regulatory proteins among these 46 genes, we predicted causal relations between the TFs and downstream genes with high accuracy and constructed a gene regulatory network. We inferred the causal relations by leveraging our transcriptome data with a regression tree algorithm RTP-STAR (Fig 2B) (Huynh-Thu et al., 2010; Spurney et al., 2020; Van den Broeck et al., 2020). The inferred network contained 20 nodes, of which four are TFs (Fig 2B). These four TFs are: WIP DOMAIN PROTEIN 4 (WIP4), which is shown to be important for root initiation, INDOLE-3-ACETIC ACID INDUCIBLE 33 (IAA33), ANGUSTIFOLIA (AN3) / GRF-INTERACTING FACTOR 1 (GIF1), which is a known regulator of cell proliferation, and an unknown TF (AT1G75710). Among the inferred AN3 targets, we confirmed with TChAP data that three targets (AT1G75710, FLA10, and GBSS1) were directly bound by AN3 (Vercruyssen et al., 2014). Network inference allowed us to identify potential functionally important genes, however, we still needed to pinpoint the biological important genes within the network.

To identify which genes could cause the largest impact on network stability when perturbed, we performed a node importance analysis. To calculate the impact of each gene, each node received a weight depending on its outdegree (i.e. number of outgoing edges), then for each node, the sum of the weighted outgoing first neighbors and the sum of the weighted incoming first neighbors was taken. Both sums were in turn weighted, specifically, the sum of the outgoing neighbors was weighted by Average Shortest Path Length (ASPL), and the sum of the incoming neighbors was weighted according to the proportion of end-nodes within the network, which is in this network 20\% (see Materials and Methods). We next developed an R-based Shiny application (Node Analyzer) that calculates the weights and impacts of each gene within a network (Shannon et al., 2003) (see Materials and Methods) (Supplemental Fig 1). Node Analyzer allowed us to rank the 20 genes in the network and select key genes. The most impactful gene within our network is $A N 3$, a transcriptional coactivator that is involved in cell proliferation during leaf and flower development (Fig 2C). 


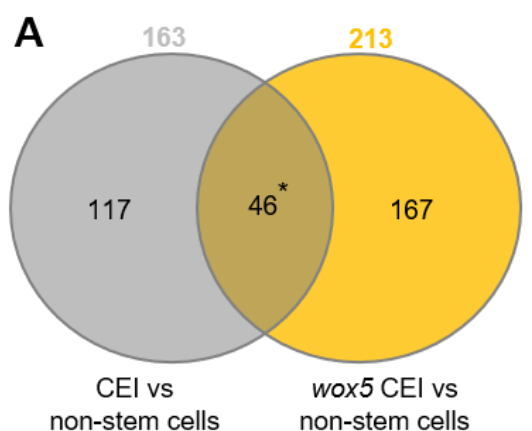

non-stem cells

non-stem cells

\section{C}

\begin{tabular}{|ccc|}
\hline Cene & Weight & Impact \\
\hline AN3 & 2.00 & 17.42 \\
IAA33 & 1.60 & 14.22 \\
AT1G75710 & 1.50 & 12.66 \\
WIP4 & 1.30 & 3.70 \\
AT5G26670 & 1.00 & 0.62 \\
AT1G65920 & 1.00 & 0.40 \\
GBS51 & 1.00 & 0.40 \\
THA2 & 1.00 & 0.40 \\
TAA1 & 1.00 & 0.40 \\
FLA10 & 1.00 & 0.40 \\
\hline
\end{tabular}

B

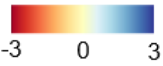
$\underset{\text { AT } 3 G 51750}{\text { AT } 1 \text { G59740 }}$

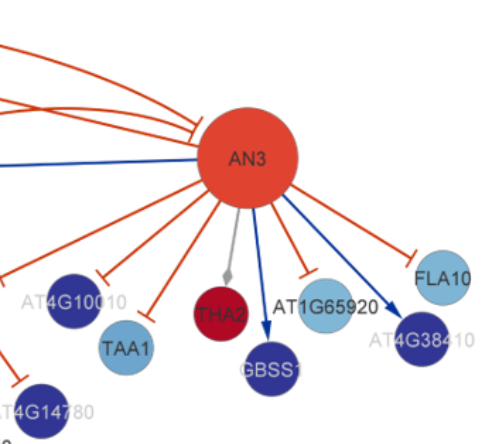

\begin{tabular}{|ccc|}
\hline Gene & Weight & Impact \\
\hline AT4G10010 & 1.00 & 0.40 \\
AT4G38410 & 1.00 & 0.40 \\
AT1G67020 & 1.00 & 0.32 \\
AT2G38510 & 1.00 & 0.32 \\
MLP28 & 1.00 & 0.32 \\
AT1G72180 & 1.00 & 0.30 \\
AT5G16960 & 1.00 & 0.30 \\
AT4G14780 & 1.00 & 0.26 \\
AT1G59740 & 1.00 & 0.26 \\
AT3G51750 & 1.00 & 0.26 \\
\hline
\end{tabular}

Figure 2 - Network analysis of CEI-expressed genes. (A) The overlap between genes differentially expressed between CEI cells and non-stem cells in the wild-type and the wox5 background. ${ }^{*}=p<0.001$ (Exact hypergeometric probability). (B) Causal interactions between 46 DEGs that are enriched in the CEI cells. Green arrows and red T-arrows represent activating and repressing regulations, respectively. The size of the nodes correlates with the outdegree of that node. The color of the nodes corresponds to the $\log _{2}$ fold change in expression in the wox 5 CEl cells compared to the non-stem cells. (C) Tabular output from the Node Analyzer application presenting the weight (calculated based on outdegree) and impact (see Materials and Methods) of each gene.

\section{AN3 contributes to the regulation of CEI divisions}

It was previously shown that AN3/GIF1 and its closest homologs, GIF2 and GIF3, were expressed in the root stem cell niche (Ercoli et al., 2018). A triple mutant (gif1/2/3) displayed a disorganized QC and increased root length as a result of an increased root meristem size (Ercoli et al., 2018). We confirmed the growth repressing role of AN3 in the roots, as an3 and 35S:AN3-GFP roots showed an increased and reduced root length compared to the WT, respectively (Supplemental Fig 2A). We observed a disorganized stem cell niche in 56\% (25/45 roots) of an3 mutant roots (Supplemental Fig 2B). Additionally, an 3 mutants contained starch granules in the cells that are normally CSC, suggesting that AN3 plays a role in CSC maintenance (Supplemental Fig 2C). To determine whether AN3 also plays a role in CEI divisions, we quantified the number of undivided and divided CEI cells in 4-, 5-, and 6-dayold an 3 and WT roots. 6-day-old an 3 roots had $19.22 \%$ fewer undivided CEI cells at compared to WT $(p=0.103$, Wilcoxon test), suggesting that more CEI divisions occur in the an3 mutant (Fig $3 A)$. Additionally, when an3 is crossed with the CEI-marker pCYCD6;1:GUS-GFP, an extended expression 

of CEI divisions.
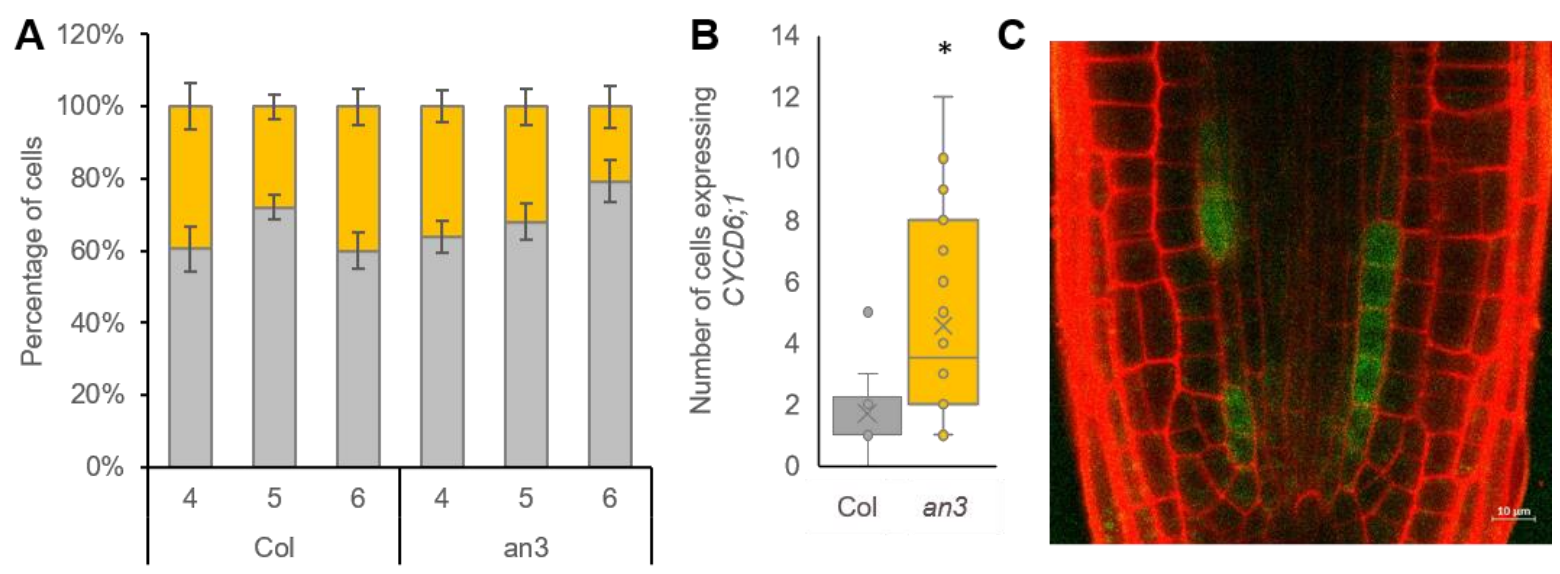

口Divided $\square$ Undivided

Figure 3 - Phenotypic analysis of an3. (A) Percentage of divided and undivided CEI cells in wild-type (Col) and an3 roots. (B) The number of endodermal and cortex cells expressing pCYCD6;1:GUS-GFP in an3xpCYCD6;1:GUS-GFP roots. (C) Confocal image of an3xpCYCD6;1:GUS-GFP root. Data are presented as mean \pm SEM. ${ }^{*}=p<0.05$ (A, B: Wilcoxon Chi-square test).

\section{A hybrid model to dynamically simulate and predict stem cell divisions}

If AN3 and WOX5 are indeed key regulators for CEI divisions, we would expect that their temporal expression influences CEI divisions in a cell-type specific manner. To gain insight into the system-level regulation of $\mathrm{CEI}$ stem cell divisions, we modeled the expression of $C Y C D 6 ; 1$ and its direct and indirect upstream regulators: SHR, SCR, WOX5, and AN3 (Fig 1C, Fig 3B) (Sozzani et al., 2010). For this we developed a hybrid model that combines agent-based modeling aspects with ODEs. Specifically, we included four different cell types or "agents" (QC, CEI, vascular initial, and endodermal cell) and constructed ODEs of the genes for each cell type that are able to recapitulate the dynamics of the upstream regulatory interactions at a molecular scale. The cells/agents interact through the movement of SHR and WOX5 and change state (i.e. divide) upon changes in the expression of specific proteins. For example, when CYCD6; 1 exceeds a certain abundance, the CEI will divide. Each time a cell divides (an agent changes state), corresponding protein abundances are halved. As such, we were able to exchange information bidirectionally, from molecular to cellular scale and from cellular to molecular scale. To implement this hybrid model we used SimBiology to model, simulate, and analyze dynamic systems that allows for rapid model optimization and provides an intuitive visualization of the model (The MathWorks, 2019).

To analyze the temporal expression dynamics of $C Y C D 6 ; 1$ linked to CEI divisions, and to understand the regulatory role of WOX5 and AN3 in controlling the CYCD6;1 dynamics, we used ODEs to generate a quantitative model that describes the dynamics of four key transcriptional regulators of CYCD6;1, 
namely WOX5, AN3, SHR, and SCR. In our ODE systems, each ODE included a degradation term and a production term that depended on its upstream regulations. The included regulations are depicted in

185 Figure 4 and are: (a) the inhibition of SHR by WOX5 in the vasculature (Clark, Fisher, et al., 2020), (b) the activation of SCR by the SHR/SCR complex in the endodermis, CEI, and QC (Heidstra et al., 2004; Helariutta et al., 2000), (c) the activation of SCR by AN3 (Ercoli et al., 2018), and (d) the activation of CYCD6;1 by the SHR/SCR complex in the CEI (Fig 4A) (Sozzani et al., 2010). As the upstream transcriptional regulations of WOX5 and AN3 are unknown, we modeled their expression based on previously published data of WOX5 and AN3 expression over time in the SCN (Clark et al., 2019). Additionally, we included ODEs that model the movement of WOX5 from the QC to the vasculature initials (Supplemental Table 3), different diffusion rates of SHR from the vascular initials to the endodermis and QC (Clark, Fisher, et al., 2020), the SHR/SCR complex formation, and the oligomeric states of WOX5 and AN3. The oligomeric states of AN3 and WOX5 were experimentally determined using scanning FCS (Supplemental Fig 3). Specifically, we performed Number and Brightness (N\&B) on an3 or wox5 roots expressing pAN3:AN3-GFP or pWOX5:WOX5-GFP translational fusion, respectively. We found that both AN3 and WOX5 primarily exist as a monomer (98.67\% and $96.01 \%$, respectively) with a very small amount of dimerization (1.33\% and 3.99\%, respectively) (Supplemental Fig 3). Thus, we fixed the oligomeric state of AN3 and WOX5 as monomers in our ODE model. As SHR and SCR dimers show a similar expression pattern as the monomers (Clark, Fisher, et al., 2020), we simplified the model and reduced the number of parameters by modeling the SHR and SCR monomer and dimer as one variable. Despite this simplification and the experimental estimation of several parameters, the number of parameters in the hybrid model still reaches over 30 as a result of its multiscale nature spanning both cellular and molecular interactions. To further reduce the number of parameters that needed to be estimated, the most influential parameters were identified with a sensitivity analysis (Sobol', 2001) (Supplemental Table 4, Supplemental Fig 4). 
A

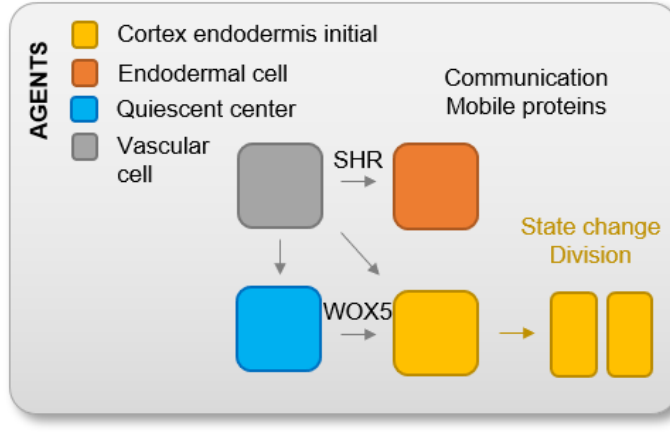

ABM

describes interacting cells

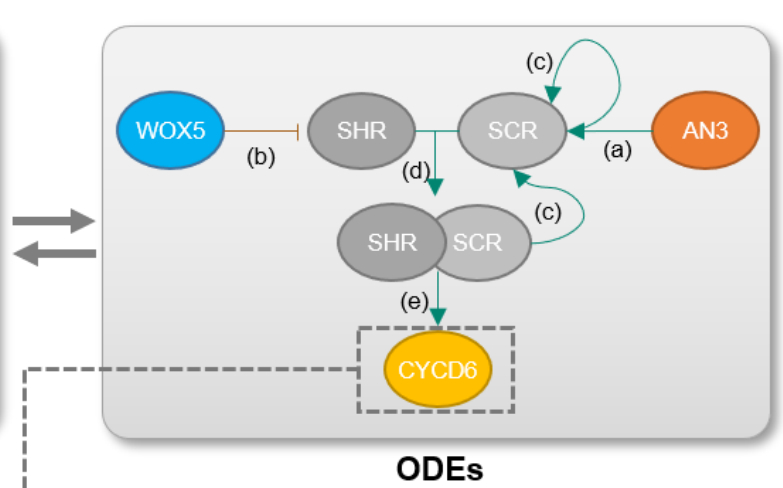

describe regulatory interactions

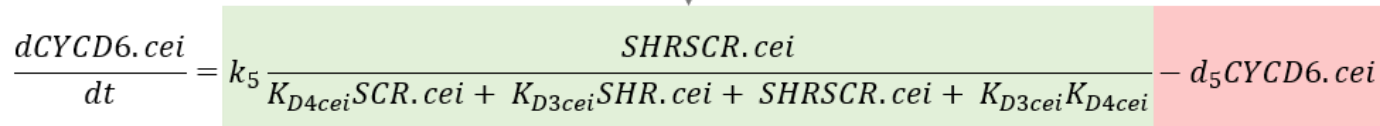

PRODUCTION TERM

Includes activation by the SHR-SCR complex (e)

DEGRADATION

TERM

B

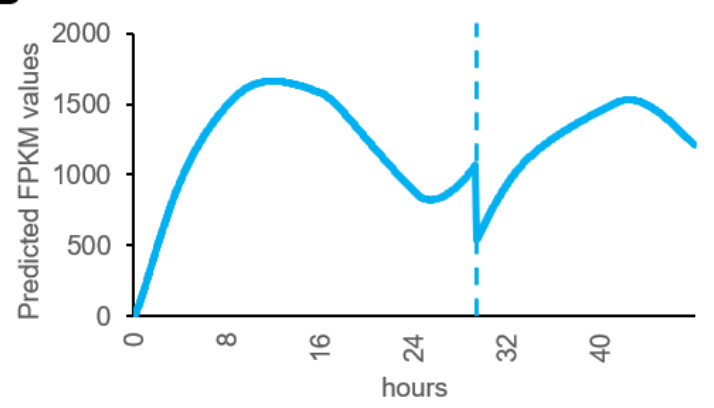

—SHR-SCR.[QC]

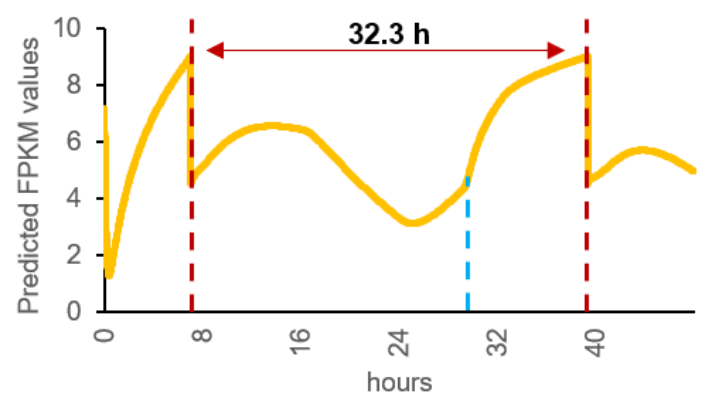

CYCD6.[CEI]

Figure 4 - Computational hybrid modeling of QC and CEI division behavior. (A) A hybrid model combines agent-based model

$(A B M)$ rules with ordinary differential equations (ODEs). Left panel: four cell types are considered as the agents in the model interacting with each other through mobile proteins and changing states through cell division. Right panel: known regulatory interactions between key genes involved in regulating CEI division [a: (Ercoli et al., 2018), b: (Clark, Fisher, et al., 2020), c: (Helariutta et al., 2000), d: (Long et al., 2017), e: (Sozzani et al., 2010)]. (B) Model simulation of the expression of SHR/SCR complex and CYCD6;1 in the QC and CEI, respectively. Red dotted lines indicate CEI divisions and the blue dotted line indicates the time point of the $\mathrm{QC}$ division.

We estimated the values for the sensitive parameters by fitting our model to computed cell-type specific time course data (Supplemental Table 5,6,7). Specifically, the expression of the modeled genes in each cell type at 5 days was extracted from cell-type specific datasets (Clark et al., 2019; Li et al., 2016) and overlaid onto a stem cell time course to obtain cell-type specific expression levels every 8 hours from 4 to 6 days (see Materials and Methods) (Supplemental Table 5). After estimating the sensitive parameters, we simulated the hybrid model to evaluate the expression dynamics within each cell. For example, the hybrid model predicts high expression of SCR in the endodermal cells and a lower expression in the CEI and QC. We confirmed the increased SCR expression in the endodermal cells by 
bioRxiv preprint doi: https://doi.org/10.1101/2020.11.30.404426; this version posted December $1,2020$. The copyright holder for this preprint (which was not certified by peer review) is the author/funder, who has granted bioRxiv a license to display the preprint in perpetuity. It is made available under aCC-BY 4.0 International license.

analyzing confocal images of the QC, CEI, and endodermal cells of pSCR:SCR-GFP for corrected total cell fluorescence (CTCF) at 5 days 16 hours (Supplemental Fig 5A,B). Model simulations showed that the cell-specific networks ensured robust stability of cellular behavior, such as cell division regulation (Fig 4B). The agent-based rules for cell division were set based on SHR/SCR complex and WOX5 expression for the QC and CYCD6;1 expression for the CEI (Supplemental Fig 6). Our hybrid model was able to capture a dynamic expression pattern for the SHR/SCR complex, with high expression at 4 days 8 hours and 5 days 16 hours. In contrast, WOX 5 shows a low expression at these time points (Supplemental Fig 5C). The first peak of SHR/SCR expression at 4 days 8 hours was previously shown in an ODE model, while the second peak occurred, compared to our model, earlier at 5 days 8 hours (Clark, Fisher, et al., 2020). Model predictions show that the fine balance between low expression of the SHR/SCR complex and WOX5 simulates a QC cell division at 5 days 5 hours. Indeed, 5- and 6-dayold plants show an increase in QC divisions compared to 4-day-old plants (Supplemental Fig 5D). Additionally, CEI divisions are predicted to occur at 4 days 8 hours and 5 days 16 hours (Fig 4B). We observed an increased percentage of divided CEls in 5-day-old roots compared to 4-day-old roots, however, an increase was not visible in 6-day-old roots compared to 5-day-old roots (Fig 1D, Fig 3A). We found that the rate of CEI divisions within our model was influenced by the QC division. For example, the change in WOX5 expression upon QC division impacts SHR expression and thus indirectly the SHR/SCR complex formation. The SHR/SCR complex, in turn, directly regulates CYCD6;1 expression which triggers CEI divisions. As such, CEI divisions are temporally correlated with the QC divisions. To test the involvement of protein movement in the interdependence of $Q C$ and CEI divisions, we quantified the CEI divisions in a wox5xpWOX5:WOX5-3xGFP line where WOX5 movement is inhibited (Berckmans et al., 2020). The number of divided CEls were decreased in the wox5xpWOX5:WOX53xGFP line, potentially the result from WOX5 repressing activities on SHR in the vascular initials (Supplemental Fig 5E,F) and, consequently, reduced levels of SHR decreases CYCD6;1 activation in the CEIs (Koizumi et al., 2012). The distinct phenotype of wox5xpWOX5:WOX5-3xGFP line compared to the wox 5 mutant phenotype, which shows an increased number of divided CEls, and the complemented wox5xpWOX5:WOX5-xGFP, suggests that WOX5 movement is key for proper CEl divisions. Taken together, our results suggest a QC division at 5 days 5 hours resulting from high SHR/SCR and low WOX 5 concentrations, CEI divisions at 4 days 8 hours and 5 days 16 hours resulting from high CYCD6;1 concentrations, and an interdependence between CEI divisions and QC divisions.

\section{The hybrid model partially captures systems behavior in response to molecular perturbations}

The regulatory network underlying the hybrid model can recapitulate the $Q C$ and CEI divisions in WT conditions. However, to further validate the model, we simulated the loss-of-function of wox5 and an 3 and evaluated the expression patterns as well as CEI division dynamics. Based on transcriptome data 
bioRxiv preprint doi: https://doi.org/10.1101/2020.11.30.404426; this version posted December 1,2020 . The copyright holder for this preprint (which was not certified by peer review) is the author/funder, who has granted bioRxiv a license to display the preprint in perpetuity. It is made available under aCC-BY 4.0 International license.

of wox5 and an3, we calculated an $99.53 \%$ and $88.12 \%$ reduction of WOX5 and AN3 expression in their respective loss-of-function lines (Supplemental Fig 7). As such, the initial expression levels of WOX5 and AN3 were set to $0.47 \%$ and $11.88 \%$ in the mutant simulation as compared to the values in a WT situation, respectively.

Model simulations of wox 5 loss-of-function predicts an additional CEI division between 4 and 5 days compared to WT, which coincides with an increase in divided CEI cells at 4 days in wox5 (Supplemental Fig 8A, Fig 1D). The additional division is most likely the result of the removal of WOX5 repression on SHR in the vascular initials leading to an accelerated accumulation of SHR/SCR complex in the CEI. An overall increase in SHR/SCR in the CEI was not predicted by the model (Supplemental Fig 9B), and accordingly, CEI-specific transcriptomics and protein quantifications in the CEI of the wox 5 mutant did not show an increased SHR expression (Supplemental Table 2, Supplemental Fig 9A). The simulations of the an3 loss-of-function predict the depletion of SCR in the QC, CEI, and endodermal cell compared to WT (Supplemental Fig 8B). This decrease in SCR expression has been shown within the QC (Ercoli et al., 2018). However, the CEI and endodermis still showed high levels of SCR when a repressor version of AN3 is expressed in the SCR reporter line (Ercoli et al., 2018), which is in contrast to the model predictions. As such, the regulation of $C Y C D 6 ; 1$ by AN3 in the CEI may not be established via SCR but another unknown mechanism. We hypothesized that AN3 is regulating an additional factor that represses CYCD6;1. For this, we added an unknown factor $\mathrm{X}$ that is activated by AN3 and represses CYCD6;1, removed the AN3 activation of $S C R$, updated the ODEs within the CEI agent accordingly, and re-estimated 4 former and 2 new parameters (see Materials and Methods) (Supplemental Table 7,8). During model optimization, an additional rule that ensured a fixed minimum time between two CEI divisions was implemented to overcome overproliferation in the model (see Materials and Methods). By adding competition between a repressor, transcriptionally activated by AN3, and the SHR/SCR direct regulation of $C Y C D 6 ; 1$, the model was able to accurately capture the CEI divisions in a wild-type situation as well as in an an3 mutant background (Fig 5A). Notably, by adding the repressor to the model, the CEI division time interval shortened to 23.3 hours (Supplemental Fig 10). To identify potential candidates as a repressor downstream of AN3, we performed genome-wide expression analysis on an3 meristematic root tissue (Supplemental Table 9). In total 1013 genes were differentially expressed $(q<0.05)$ including 67 TFs of which 4 TFs were shown to interact with TOPLESS $(T P L)$, a known transcriptional corepressor (Causier et al., 2012) (Fig 5B). Of these 4 transcriptional repressors, WRKY30 and MYB7 showed the highest expression correlation with the model prediction (Fig 5C). WRKY30 and MYB7 were also identified as a downstream target of AN3 in a tandem chromatin affinity purification (TChAP) experiment (Vercruyssen et al., 2014). AtAUX2-11 and RVE1 showed no correlation and anti-correlation with the model predictions, respectively. As such, we propose WRKY30 
bioRxiv preprint doi: https://doi org/10.1101/2020.11.30.404426; this version posted December $1,2020$. The copyright holder for this preprint (which was not certified by peer review) is the author/funder, who has granted bioRxiv a license to display the preprint in perpetuity. It is made available under aCC-BY 4.0 International license.

or MYB7 as the putative downstream target of AN3 and repressor of $C Y C D 6 ; 1$ in the model. Our hybrid model suggests that the regulation of CEI divisions by AN3 does not occur through its regulation of $S C R$. Model predictions propose an unknown repressor activated by AN3 that is able to control CYCD6;1 expression. Overall, we modeled systemic behavior and predicted SCR, SHR, WOX5, AN3, and CYCD6;1 cell-type-specific protein concentrations as well as QC and CEI division dynamics.
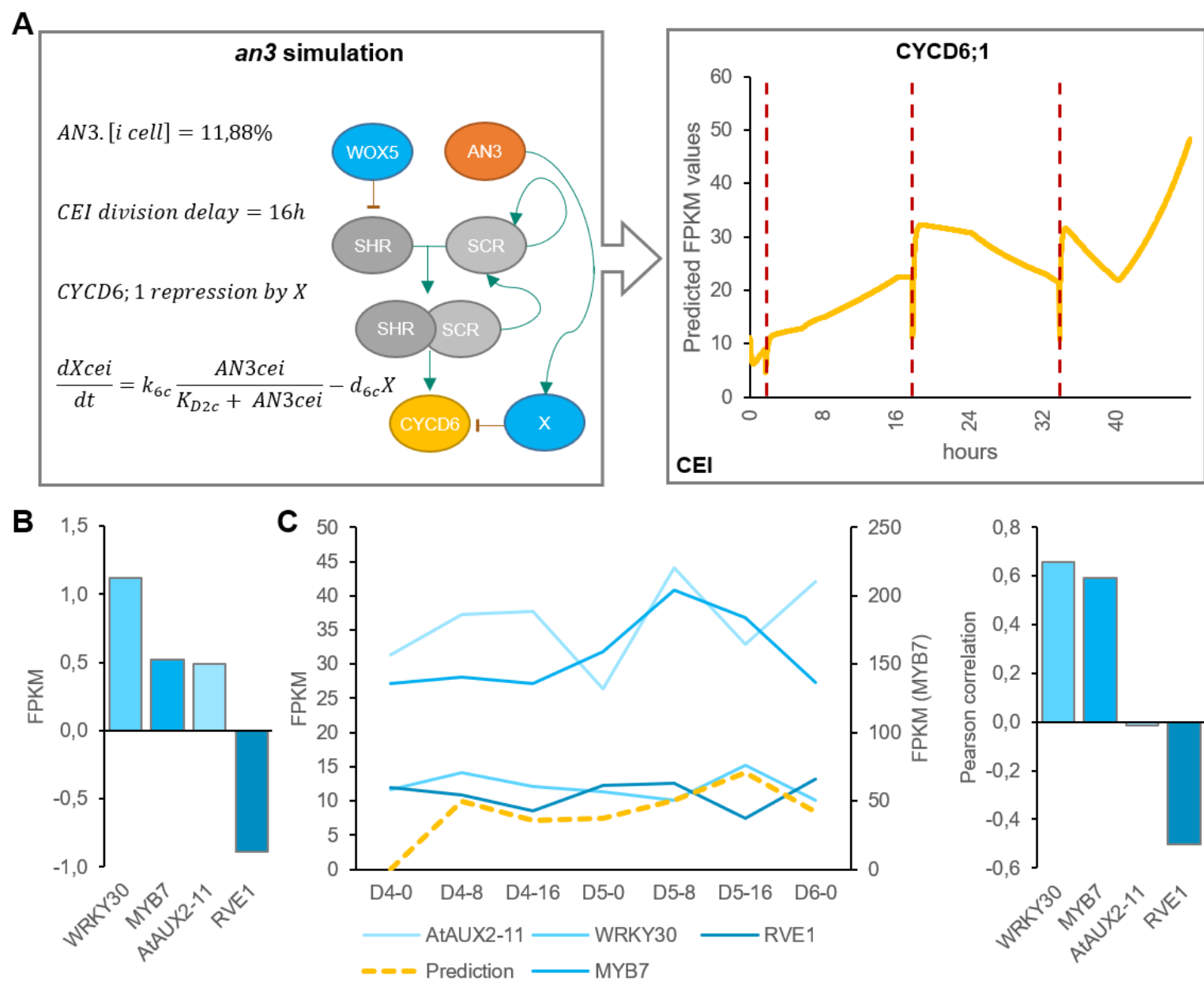

Figure 5 - Mathematical modeling of CEI behavior in the an3 mutant background. (A) Left panel indicates the modifications made to the model. Right panel shows the CYCD6; 1 expression during the an3 simulation in the CEI agent. Red dotted lines indicate a division. (B) The expression values of transcriptional repressors within the an 3 transcriptome dataset identified through overlap with the TOPLESS interactome. (C) The expression of the four identified transcriptional repressors in the an 3 mutant within the stem cell time course (left) and Pearson correlation with the model predicted FPKM values (right). FC = fold change, $\mathrm{CEI}=$ cortex endodermal initial.

\section{Discussion}

Plants are multiscale systems in which cellular processes, such as the divisions of cells, occur at a different timing than molecular processes, such as protein movement. To understand these multiscale systems and connect molecular dynamics with phenotypic changes, models that take into account multiple scales are becoming increasingly important. We have proposed an ODE and agent-based 
bioRxiv preprint doi: https://doi.org/10.1101/2020.11.30.404426; this version posted December 1,2020 . The copyright holder for this preprint (which was not certified by peer review) is the author/funder, who has granted bioRxiv a license to display the preprint in perpetuity. It is made available under aCC-BY 4.0 International license.

hybrid model that allows for the exchange of information across biological scales, from a molecular scale (i.e. regulatory interactions at single cell level) to a cellular scale (i.e. division of stem cells). As such, protein abundances have a direct influence on cell divisions and vice versa. Additionally, the cell divisions within the model could be triggered by the expression dynamics of regulatory networks within each cell.

In the Arabidopsis root stem cell niche ( $\mathrm{SCN}$ ), the different stem cell types and the quiescent center (QC) are positioned in a highly regular and well-characterized organization. The asymmetric divisions of these organized stem cells form all cell- and tissue-types of Arabidopsis root and are controlled by dynamic, yet robust, regulatory signaling mechanisms. Several transcription factors (TFs) have been identified in a cell-type specific context to regulate stem cell divisions. For example, SHR and SCR are known to activate CYCD6;1 in the cortex endodermis initials (CEI) (Sozzani et al., 2010) and, in this study, we propose a non-cell autonomous function for WOX5 in the regulation of CEI divisions. The extended expression pattern of $C Y C D 6 ; 1$ into both the endodermis and cortex cells proximal of the CEI in wox5 has, to our knowledge, not yet been observed. However, treating wild-type plants with auxin results in an extended CYCD6;1 expression pattern solely into the endodermis, coinciding with additional periclinal divisions (Cruz-Ramírez et al., 2012). Similarly, increased CYCD6;1 expression into the endodermis in the upper ground tissue was observed in an RNAi line of MEDIATOR 31 (MED31) (Zhang et al., 2018). However, the function of key proteins, such as WOX5 and SHR, on a system-level scale is unknown and key questions remain: How do key regulatory proteins coordinately regulate stem cell divisions? What set of rules and parameters govern these complex systems? In this study, we have used a multiscale hybrid model to advance research that aims to connect molecular dynamics with phenotypic changes. The connection between regulatory inputs and cellular behavior, such as cell division, is highly complex and requires computational models to generate and test hypotheses about the rules governing these cellular behaviors. The hybrid model allowed us to describe complex systemic behavior by combining: (1) discrete agent-based modeling aspects to incorporate cellspecificity and allow for cell divisions through simple rules, and (2) continuous ODE models to describe the expression dynamics of the included proteins. Including interactions between agents/cells is critical to fully address system-level problems and replicate observable behaviors. Questions about how mobile proteins affect phenotypic changes can be addressed by instructing agents/cells to communicate effectively in a model. To note, this model is not attempting to simulate and predict the division plane or direction. The ODE and agent-based hybrid model includes short range signals allowing for cell-to-cell communication. The mobile proteins, WOX5 and SHR, non-cell-autonomously regulate the expression of downstream proteins in specific cell types and allow for the communication between these cell types. WOX5 proteins can move to the neighboring vascular initials and CEI cells 
bioRxiv preprint doi: https://doi org/10.1101/202011.30.404426; this version posted December 1,2020 . The copyright holder for this preprint (which was not certified by peer review) is the author/funder, who has granted bioRxiv a license to display the preprint in perpetuity. It is made available under aCC-BY 4.0 International license.

and SHR proteins move to the QC, CEl, and endodermal cells. Scanning FCS was used to quantify the diffusion coefficient of WOX5 and SHR to include into the model (Supplemental Table 7) (Clark et al., 2016; Clark, Van den Broeck, et al., 2020). As such, the model predicted an additional CEI division in wox5 mutant as a result of the non-cell-autonomous regulation of SHR by WOX5 in the vascular initials and the movement of SHR to the CEI. Importantly, the inclusion of cell-to-cell communication into the model was crucial to accurately model stem cell division dynamics and contributed towards a better understanding of the rules underlying cellular behavior.

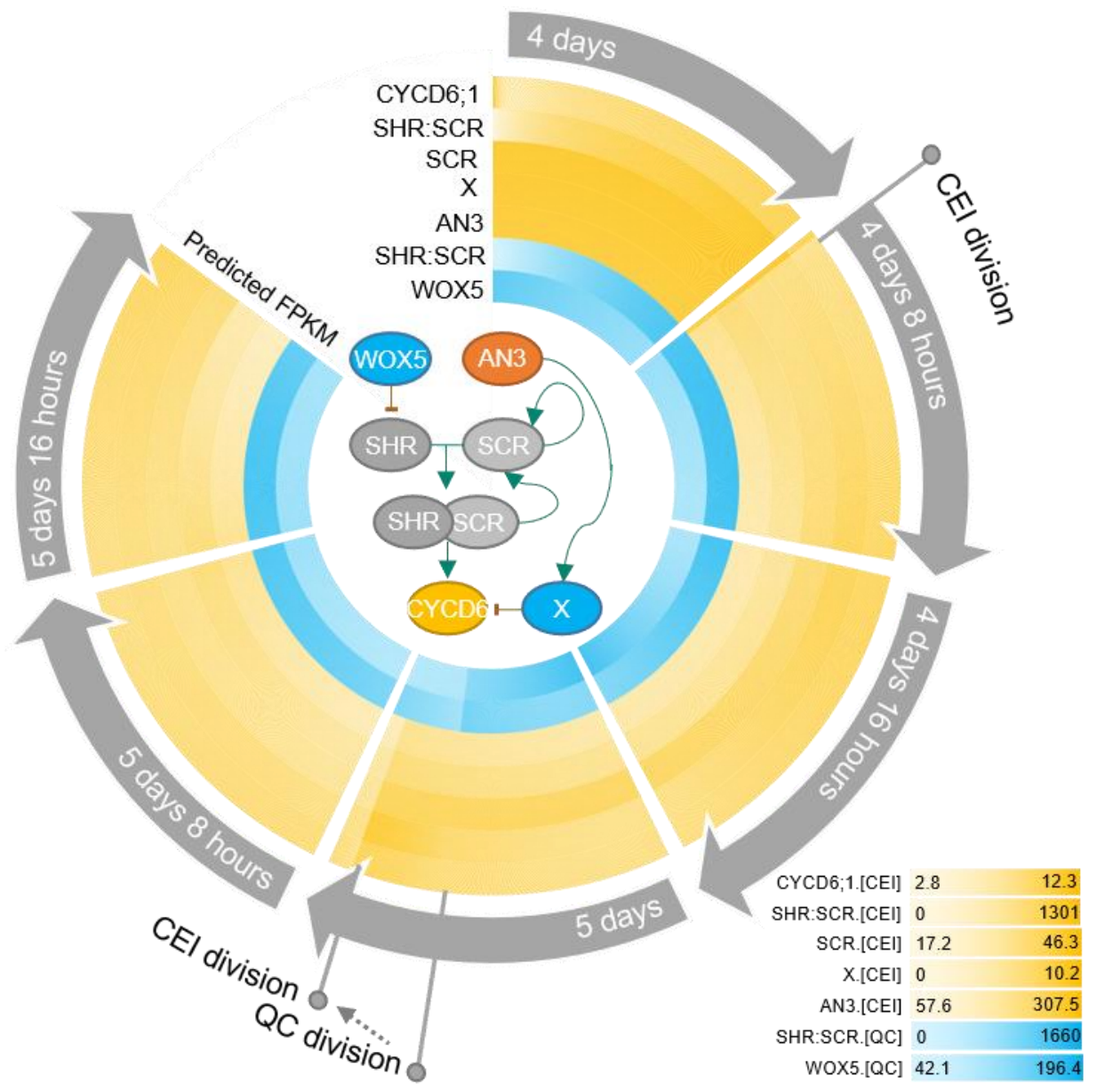

Figure 6 - Overview of stem cell division dynamics. Circular heatmap of the predicted FPKM of WOX5, SHR/SCR, AN3, CYCD6;1-repressor $X, S C R$, and $C Y C D 6 ; 1$ over time from 4-day-old roots up to 6-day-old roots. The yellow and shades are predicted FPKM in the CEI and the QC, respectively. CEI and QC divisions are marked upon the heatmap. In the middle of the circular heatmap, a network with the known and predicted regulatory interactions between these key proteins is drawn. Green and red arrows represent activation and repression, respectively.

Overall, our computational models and approach was aimed at making predictions about the rules of stem cell divisions that lead to testable hypotheses and assist in making future decisions. Accordingly, since the model suggested that the CEI-specific role of AN3 was not established through the regulatory interaction with SCR, we implemented a transcriptional repressor regulated by AN3, a non-intuitive aspect, to simulate the additional CEI divisions as found in an an3 background. Four candidate 
transcriptional repressors (Causier et al., 2012) downstream of AN3 and upstream of CYCD6;1 were proposed based on transcriptome analysis, of which WRKY3O and MYBT showed the highest correlation with model predictions and were identified as a downstream target of AN3 in a TChAP experiment (Vercruyssen et al., 2014). Even though, since this is outside the scope of the study, the roles of these four TFs in regulating stem cell division within the SCN remains elusive, our integrative multiscale model allowed us to both 1) predict cellular behavior in normal conditions; and 2) capture CEI division dynamics in response to perturbations. Thus, by combining continuous models to describe cell-specific regulatory networks and agent-based rules, systemic behavior was modeled and led to a deeper understanding of the regulatory rules governing cell division.

\section{Materials and methods}

Plant material and growth conditions

The wox5 and an3 loss-of-function lines, pAN3:AN3-GFP, 35S-AN3-GFP, pWOX5:WOX5-GFP pCYCD6;1:GUS-GFP, and wox5 x pCYCD6;1:GUS-GFP are previously described in (Clark, Fisher, et al., 2020; Ercoli et al., 2018; Sozzani et al., 2010; Vercruyssen et al., 2014). an3 x pCYCD6;1:GUS-GFP was generated by crossing an3 with pCYCD6;1:GUS-GFP. Homozygous plants were selected by PCR using the SALK LB primer and the AN3-specific oligos 5'-ATTACGACACAACTTGGAGCC-3' and 5'TTTGTGGTCCGAAACAACATC-3'. All lines were upscaled with their corresponding wild type.

For imaging and root growth assays, seeds were dry sterilized using fumes produced by a solution of $100 \%$ bleach and $1 \mathrm{M}$ hydrochloric acid. The seeds were plated on square Petri dishes with solid $(10 \mathrm{~g} / \mathrm{L}$ agar, Difco ${ }^{\mathrm{TM}}$ ) 1X MS (Murashige and Skoog) medium supplemented with $1 \%$ sucrose and stratified for 2 days at $4^{\circ} \mathrm{C}$. The plates were grown vertically at $22^{\circ} \mathrm{C}$ in long-day conditions (16-hrs light/ 8-hrs dark) for $4,5,6$, or 7 days as indicated in the figures. At least three biological replicates of 10 to 20 plants were performed for the root growth assays and confocal images. The different lines were always grown together on one plate with the appropriate control line. For RNAseq experiments, seeds were wet sterilized using 50\% bleach, 100\% ethanol, and water. Seeds were imbibed and stratified for 2 days at $4^{\circ} \mathrm{C}$. Next, the seeds were plated with high density on Nitex mesh squares on top of solid $1 \mathrm{X}$ MS medium with $1 \%$ sucrose. Seeds were plated and grown vertically at $22^{\circ} \mathrm{C}$ in long-day conditions.

\section{Root growth assays}

At $3,4,5,6$, and 7 days, the primary root length was marked. At 7 days, a picture of the marked square plates was taken and the root length was measured using the software program ImageJ version 1.45

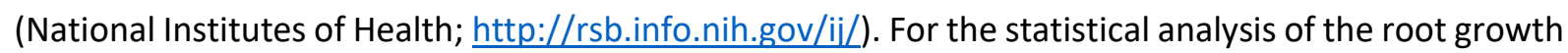
assays, Student's t-tests were performed on the average of each biological replicate. 
bioRxiv preprint doi: https://doi.org/10.1101/2020.11.30.404426; this version posted December 1, 2020. The copyright holder for this preprint (which was not certified by peer review) is the author/funder, who has granted bioRxiv a license to display the preprint in perpetuity. It is made available under aCC-BY 4.0 International license.

Confocal microscopy was conducted using a Zeiss LSM 710 or 880 on 4, 5, or 6 day-old root tips. The $488 \mathrm{~nm}$ and $570 \mathrm{~nm}$ lasers were used for green and red channel acquisition, respectively. Propidium

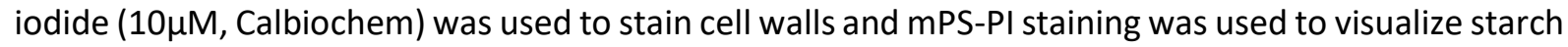
granules. For the N\&B acquisition, 12-bit raster scans of a $256 \times 256$ pixel region of interest were acquired with a pixel size of $100 \mathrm{~nm}$ and a pixel dwell time of $12.61 \mu$ s as described in (Clark et al., 2016; Clark \& Sozzani, 2017). For pair correlation function (pCF) acquisition, 100000 12-bit line scans of a $32 \times 1$ pixel region of interest were acquired with a varying pixel size and a pixel dwell time of $8.19 \mu$ s as described in (Clark et al., 2016; Clark \& Sozzani, 2017). Heptane glue was used during N\&B and pCF acquisition to prevent movement of the sample as described in (Clark et al., 2016; Clark \& Sozzani, 2017).

Analysis of confocal images for corrected total cell fluorescence (CTCF) measurements was performed as described previously (Clark et al., 2019). Analysis of the raster scans acquired for N\&B and the line scans for pCF was performed using the SimFCS software (https://www.Ifd.uci.edu/globals/). For N\&B, the 35S:GFP line was used to normalize the background region of the image (S-factor of 2.65) and determine monomer brightness (brightness of 0.26 ). A $128 \times 128$ region of interest was used on all images to measure oligomeric state specifically in the QC. For pCF, each line scan image was analyzed with three different pixel distances $(8,10$ and 12 , or 7,9 and 11) in both a left-to-right (movement from $\mathrm{QC}$ to $\mathrm{CEI}$ ) and a right-to-left scanning direction (movement from CEI to $\mathrm{QC}$ ). For each technical replicate of a line scan image, a qualitative Movement Index (MI) was assigned based on the detection of movement in the carpet (arch pattern, $\mathrm{MI}=1$ ) or not (no arch pattern, $\mathrm{MI}=0$ ) (Clark et al., 2016; Clark \& Sozzani, 2017). The technical replicates were then averaged for each biological replicate. The pWOX5:WOX5:GFP images were analyzed separately in both directions.

\section{RNAseq analysis and network inference}

Three hundred to five hundred mg of pWOX5:erGFP, pCYCD6:GUS-GFP, and wox5 x pCYCD6:GUS-GFP seeds were wet sterilized and plated for each of the four biological replicate. After 5 days of growth, approximately $1 \mathrm{~mm}$ of the root tip was collected and protoplasted as described (Birnbaum et al., 2005). GFP positive and negative cells were collected using a MoFlo cell sorter into a vial containing a solution of beta-mercaptoethanol and RLT buffer. RNA was extracted using the Qiagen RNeasy Micro kit. Libraries were prepared using the SMART-Seq v3 Ultra Low RNA Input Kit for Sequencing and the Low Library Prep Kit v1 from Clontech. For the an3 RNAseq experiment, $\sim 5 \mathrm{~mm}$ of an3 and WT root tips were collected for each of the three biological replicates. RNA was extracted using the Qiagen RNeasy Micro kit and libraries were prepared using the NEBNext Ultra II RNA Library Prep Kit for Illumina (New England BioLabs). All libraries were sequenced on an Illumina HiSeq 2500 with 100 bp single-end reads. 
427 Gene expression analysis of raw RNA-seq data and subsequent GRN inference was performed using

428 the TuxNet interface (Spurney et al, 2019). Specifically, TuxNet uses ea-utils fastq-mcf (Aronesty, 2011,

429 Aronesty, 2013) for preprocessing, hisat2 (Kim et al, 2015) for genome alignment, and Cufflinks

430 (Trapnell et al, 2012) for differential expression analysis. To infer a gene regulatory network (GRN) and

431 predict the causal relationships of genes regulating CEI identity, differentially expressed genes (DEGs)

432 were identified using $q<0.05$ as our selection criteria, when performing pairwise comparisons

433 between GFP negative cells from pWOX5:erGFP and GFP positive cells from pCYCD6:GUS-GFP or wox5

$434 \times$ pCYCD6:GUS-GFP. Within the TuxNet interface, RTP-STAR (Regression Tree Pipeline for Spatial,

435 Temporal, and Replicate data) was used for all network inference. The pipeline consists of three parts:

436 spatial clustering using the k-means method, network inference using GENIE3, and edge sign

437 (activation or repression) identification using the first order Markov method. TuxNet is available at

438 https://github.com/rspurney/TuxNet and video tutorials regarding installation, analysis, and network

439 inference are freely available at https://rspurney.github.io/TuxNet/. The network was visualized in

$440 \quad$ Cytoscape $^{\circledR}$ 3.8.0 (Shannon et al., 2003).

441

\section{Node impact analysis}

Each node from the network receives a weight between 1 and 2:

$$
\operatorname{weight}(N)=w=1+\frac{O}{O_{\max }}
$$

Nodes with a high outdegree $(0)$ are considered to be more impactful within the network and will thus receive a high weight. The impact of a node within the network topology is calculated based on the weighted first neighbors:

$$
\begin{gathered}
R=A S P L \times \sum_{1 \text { to } O}^{i} w_{i}+A \times \sum_{1 \text { to } I}^{i} w_{i} \\
A=\frac{\text { Nodes (outdegree }>0)}{\text { Nodes }}
\end{gathered}
$$

where $R=$ Robustness, $A S P L=$ Average Shortest Path Length, $O=$ outdegree, and $I=$ indegree. A scalefree network will have a low $A$, while a scale-rich network will have a high $A$, allowing for the indegree to contribute more to the impact of a node. Because the first neighbors are weighted in regards to their outdegree, genes with a lower outdegree can still have a large impact if its neighbors have a high outdegree and the gene is thus centrally located. Genes with a large number of cascading targets that are 2 or more nodes away will have a higher ASPL and thus a higher scaled outdegree weight, accurately reflecting the hierarchical importance of the source gene itself and its first neighbors targets. 


\section{Shiny app: Node Analyzer}

To calculate necessary network statistics such as outdegree and indegree in Cytoscape ${ }^{\circledR}$ 3.8.0 (Shannon et al., 2003), select Tools -> Analyze Network, check the Analyze as Directed Graph if applicable, and then press OK to perform the analysis. To export node and edge files from Cytoscape, select File -> Export -> Table to File, and then choose default edge or default node in the 'Select a table to export' dropdown. Press OK to export each file. Import the node and edge table files into the corresponding prompts (Fig 2C) and press the Run Analysis button to calculate impact scores. Results can be downloaded as a table using the Download Results button. In addition to the impact scores, the application renders three plots for visualization: one plot with the impact score for each gene and two histograms with the indegree and outdegree.

The Node Analyzer user interface can be accessed online at https://rspurney.shinyapps.io/nodeanalyzer/ or ran through $\mathrm{R}$ with scripts freely available at https://github.com/rspurney/NodeAnalyzer. Example datasets are also available via the GitHub link.

Ordinary equations, parameter estimation, and sensitivity analysis

Ordinary differential equations (ODEs) were developed to model the dynamics of CYCD6;1, its upstream regulators SHR and SCR, WOX5, and AN3 in three different cell types: endodermal cells, CEI, and QC. The regulatory interactions between these five proteins were modeled using Hill equation dynamics, and SHR-SCR complex formation is modeled using mass-action kinetics. SHR and WOX5 diffusion are modeled using a linear term for gradient-independent diffusion. All proteins are assumed to have a linear degradation term. We modeled transcriptional regulation and protein expression in the same equation.

(1) SHR; for the upstream regulation of SHR in the vasculature, the repression by WOX5 was included (top equation) (Clark, Fisher, et al., 2020).

$$
\frac{d S H R .[\text { vasc }]}{d t}=k_{4} \frac{K_{\text {D1vasc }}}{K_{\text {D1vasc }}+\text { WOX } 5 .[\text { vasc }]}-d_{4} S H R .[\text { vasc }]
$$

(2) SCR; for the upstream regulation of SCR expression, we included the autoactivation by SCR itself (Cruz-Ramírez et al., 2012; Heidstra et al., 2004), the activation by the SCR-SHR complex (Heidstra et al., 2004), and the activation by AN3 (Ercoli et al., 2018). Each one of these regulations was assumed to be sufficient to induce $S C R$ expression.

$$
\begin{aligned}
\frac{d S C R .[i \text { cell }]}{d t}= & k_{3 i}\left(\frac{K_{D 4 i} S C R .[\text { i cell }]+S S C .[\text { i cell }]}{K_{D 3 i} K_{D 4 i}+K_{D 4 i} S C R .[i \text { cell }]+K_{D 3 i} S H R .[i \text { cell }]+S S C .[\text { i cell }]}\right. \\
& \left.+\frac{A N 3 .[i \text { cell }]}{K_{D 2 i}+A N 3 .[i \text { cell }]}\right)-d_{3 i} S C R .[i \text { cell }]
\end{aligned}
$$


(3) WOX5; the production of WOX5 was assumed to be time-dependent as this produces the best model fit to the experimental data (top equation) (Clark, Fisher, et al., 2020).

$$
\frac{d W O X 5 \cdot[Q C]}{d t}=k_{1 q c} W O X 5 .[Q C]
$$

(4) AN3; the production of AN3 was assumed to be time-dependent as this produces the best model fit to the experimental data.

$$
\frac{d A N 3 .[\text { i cell }]}{d t}=k_{2 i} A N 3 .[\text { i cell }]
$$

(5) CYCD6;1; for the upstream regulation of $C Y C D 6 ; 1$ expression, we included the activation by the SCR-SHR complex (Sozzani et al., 2010).

$$
\frac{d C Y C D 6 .[C E I]}{d t}=k_{5} \frac{S S C .[C E I]}{K_{D 4 c e i} S C R .[C E I]+K_{D 3 c e i} S H R .[C E I]+S S C .[C E I]+K_{D 3 c e i} K_{D 4 c e i}}-d_{5} C Y C D 6 .[C E I]
$$

It was shown that the different oligomeric forms and stoichiometries of SHR, SCR, and the SCR-SHR complex show a similar expression pattern (Clark, Fisher, et al., 2020). As such, the SHR and SCR oligomeric forms were modeled as one variable.

The interaction between the different agents/cell types is modeled using mass-action kinetics. The state change following division is modelled using simple agent-based rules. To simulate division of an agent, the capacity of the cell doubles, subsequently halving all proteins present.

(6) The cell types interact with each other through the movement of the regulatory proteins SHR and WOX5. The amount of SHR in the other cell types was determined by the movement of SHR (top equation). The amount of WOX5 in the vasculature was determined by the movement of WOX5 from the QC (bottom equation) (Fig 1).

$$
\begin{gathered}
\frac{d S H R \cdot[\text { i cell }]}{d t}=a_{i} S H R .[\text { vasc }]-d_{12 i} S H R .[\text { i cell }] \\
\frac{d W O X 5 .[\text { vasc }]}{d t}=a_{\text {vasc } W O X 5 .[Q C]-d_{1 v a s c} \text { WOX } 5 .[\text { vasc }]}
\end{gathered}
$$

(7) It was shown that the division of the QC cell correlates with the expression of WOX5 and the SCR-SHR complex (Clark, Fisher, et al., 2020).

$$
\text { if WOX5. }[Q C] \leq 100 \& \text { SSC. }[Q C] \leq 1100: \frac{\text { Gene }_{0 \text { to } j} \cdot[Q C]}{2}
$$

(8) We assumed that the division of the CEI cells is dependent on the expression of CYCD6;1 (Sozzani et al., 2010).

$$
\text { if } C Y C D 6 .[C E I] \geq 9: \frac{\text { Gene }_{0} \text { to } j \cdot[C E I]}{2}
$$


For the sensitivity analysis, the total Sobol effect index was calculated for each parameter value (Saltelli et al., 2010; Sobol', 2001). Parameter values were randomly sampled using Monte Carlo sampling to obtain 150 different values for each parameter. This analysis was repeated for 10 technical replicates. As such, for each parameter 170 (10 replicates $\times 17$ ODEs) total Sobol effect indices were obtained. For each ODE and replicate the sensitivities were rescaled between 0 and 1 and then averaged across the 17 ODEs. The obtained averaged sensitivities for each replicate were again averaged to retrieve the total Sobol effect index per parameter (Supplemental Table 4). The sensitive parameters were chosen as the parameters that had significantly higher Sobol indices than the lowest scoring parameter (K_D2_qc) using a student's t-test $(p<0.01)$.

To estimate the sensitive parameters, the model was fitted onto extrapolated cell-type specific time course expression data (Supplemental Table 5). To generate this cell-types specific time course expression data, FPKM values in the QC, CEI and vascular initials at 5 days were obtained from Clark et al, and the endodermis specific FPKM values at 5 days were obtained from Li et al (Clark et al., 2019; Li et al., 2016). Using the fold changes of a time course dataset from the root stem cell niche every 8 hours from 4 to 6 days (Clark et al., 2019) and the FPKM values at 5 days for the specific cell types, we were able to extrapolate cell-type specific time course expression values (Supplemental Table 5). Simulated annealing and Latin hypercube sampling as described in (Clark, Fisher, et al., 2020) produced 40 sets parameter estimates (Supplemental Table 6). The average of these parameter estimates was used for the model simulations. The remaining sensitive parameters were set to a constant value from the corresponding estimated parameter in (Clark, Fisher, et al., 2020). The value of non-sensitive parameters was selected based on similar values of the model described in (Clark, Fisher, et al., 2020). The production terms for WOX5 (k1_qc) and AN3 (k2_qc, k2_cei, k2_endo) were set to a constant value at each time point to minimize the error between the model and the time course expression data. The diffusion coefficients of SHR (a_qc, a_cei) and WOX5 (b_qc) were experimentally determined from RICS experiments (Supplemental Table 3) (Clark, Fisher, et al., 2020).

The following changes were made in the regulatory network underlying the CEI divisions to reflect the an3 loss-of-function in the hybrid model:

(1) Factor $\mathbf{X}$; for the upstream regulation of the unknown repressor $\mathbf{X}$ in the CEI agent, the activation by AN3 was included.

$$
\frac{d X .[C E I]}{d t}=k_{6 c e i} \frac{A N 3 .[C E I]}{K_{D 2 c e i}+A N 3 .[C E I]}-d_{6 c e i} X .[C E I]
$$

(2) CYCD6;1; for the upstream regulation of $C Y C D 6 ; 1$ expression, we added the repression of factor $X$ in addition to the activation by the SCR-SHR complex (Sozzani et al., 2010). 


$$
\begin{aligned}
\frac{d C Y C D 6 .[C E I]}{d t}= & k_{5}\left(\frac{S S C \cdot[C E I]}{K_{D 4 c e i} S C R \cdot[C E I]+K_{D 3 c e i} S H R .[C E I]+S S C \cdot[C E I]+K_{D 3 c e i} K_{D 4 c e i}}\right. \\
& \left.+\frac{K_{D 6 c e i}}{K_{D 6 c e i}+X .[C E I]}\right)-d_{5} C Y C D 6 .[C E I]
\end{aligned}
$$

(3) SCR; for the upstream regulation of SCR expression in the CEI and endodermal agent, we included the autoactivation by SCR itself (Cruz-Ramírez et al., 2012; Heidstra et al., 2004), the activation by the SCR-SHR complex (Heidstra et al., 2004), and removed the activation by AN3 (Ercoli et al., 2018).

$$
\frac{d S C R .[\text { i cell }]}{d t}=k_{3 i} \frac{K_{D 4 i} S C R .[i \text { cell }]+S S C .[\text { i cell }]}{K_{D 3 i} K_{D 4 i}+K_{D 4 i} S C R .[i \text { cell }]+K_{D 3 i} S H R .[i \text { cell }]+S S C .[i \text { cell }]}-d_{3 i} S C R .[i \text { cell }]
$$

(4) To avoid uncontrollable division within the CEI, the CEI agent was subjected to an additional rule that ensured a minimum time of $16 \mathrm{~h}$ between successive divisions $(\Delta t)$.

$$
\text { if } C Y C D 6 .[C E I] \geq 9 \& \Delta t>16: \frac{\text { Gene }_{0} \text { to } j \cdot[C E I]}{2}
$$

Four existing parameters (k3_endo, d3_endo, k3_cei and k5_cei) and two new parameters (k6_cei, d6_cei) were re-estimated in the same manner as described above and produced 20 sets parameter estimates (Supplemental Table 8). For the remaining parameters the same value as the initial hybrid model was used.

All parameters for the initial and adjusted model are listed in supplemental table 7. To simulate the hybrid models, the initial values were set as the 4D FPKM values from the extrapolated time course data. For factor X, the SHR/SCR complex, and very lowly expressed genes (e.g. WOX5 in the vascular initials) the initial value was zero. To simulate wox5 loss-of-function the initial value of WOX5 was set to $0.47 \%$ (Supplemental Fig 7). To simulate an3 loss-of-function the initial value of AN3 in all three agents, was set to $11.88 \%$ (Supplemental Fig 7). ODE45 was used as the ODE solver within SimBiology.

Data and Coding Availability

567 All sequencing data are available on GEO at:

- https://www.ncbi.nlm.nih.gov/geo/query/acc.cgi?acc=GSE155462: access token atqloyuybzufhon - https://www.ncbi.nlm.nih.gov/geo/query/acc.cgi?acc=GSE155463: access token ohmtgieydvcdruf

MATLAB code used for the hybrid model is available at

571 https://github.com/LisaVdB/Hybrid model CEl division. R-code used to develop the Shiny application is available at https://github.com/rspurney/NodeAnalyzer.

\section{Acknowledgements}

574 We thank Dr. Kensuke Kawade for an3 seeds, Dr. Javier F. Palatnik for the pAN3:AN3-GFP seeds, Dr. 


\section{Author Contributions}

577 L.V.d.B., A.P.F., and R.S. conceived and designed the study. L.V.d.B. and R.J.S. conducted the 578 computational modeling. N.M.C. advised on the modeling. R.J.S designed the Shiny App. A.P.F., 579 L.V.d.B., T.T.N, I.M, and M.G gathered experimental data. L.V.d.B and A.P.F analyzed experimental 580 data. L.V.d.B performed statistical analysis. L.V.d.B, A.P.F., R.J.S, and R.S wrote the manuscript and all 581 authors contributed to correcting the manuscript.

\section{Financial Support}

583 This work was supported by the National Science Foundation (NSF) (CAREER MCB-1453130) (MCB584 1856248) to RS; Foundation for Food and Agriculture Research (FFAR) to RS; and NSF/Biotechnology 585 and Biological Sciences Research Council (BBSRC) (MCB-1517058) to TAL and RS.

\section{Conflicts of Interest declarations in manuscripts}

The authors declare no conflict of interest. 


\section{References}

Berckmans, B., Kirschner, G., Gerlitz, N., Stadler, R., \& Simon, R. (2020). CLE40 Signaling Regulates Root Stem Cell Fate. Plant Physiology, 182(4), 1776 LP - 1792. https://doi.org/10.1104/pp.19.00914

Birnbaum, K., Jung, J. W., Wang, J. Y., Lambert, G. M., Hirst, J. A., Galbraith, D. W., \& Benfey, P. N. (2005). Cell type-specific expression profiling in plants via cell sorting of protoplasts from fluorescent reporter lines. Nature Methods, 2(8), 615-619. https://doi.org/10.1038/nmeth0805-615

Canher, B., Heyman, J., Savina, M., Devendran, A., Eekhout, T., Vercauteren, I., Prinsen, E., Matosevich, R., Xu, J., Mironova, V., \& De Veylder, L. (2020). Rocks in the auxin stream: Woundinduced auxin accumulation and \&lt;em\&gt;ERF115\&lt;/em\&gt; expression synergistically drive stem cell regeneration. Proceedings of the National Academy of Sciences, 117(28), 16667 LP 16677. https://doi.org/10.1073/pnas.2006620117

Causier, B., Ashworth, M., Guo, W., \& Davies, B. (2012). The TOPLESS interactome: a framework for gene repression in Arabidopsis. Plant Physiology, 158(1), 423-438. https://doi.org/10.1104/pp.111.186999

Cilfone, N. A., Kirschner, D. E., \& Linderman, J. J. (2015). Strategies for Efficient Numerical Implementation of Hybrid Multi-scale Agent-Based Models to Describe Biological Systems. Cellular and Molecular Bioengineering, 8(1), 119-136. https://doi.org/10.1007/s12195-0140363-6

Clark, N. M., Buckner, E., Fisher, A. P., Nelson, E. C., Nguyen, T. T., Simmons, A. R., de Luis Balaguer, M. A., Butler-Smith, T., Sheldon, P. J., Bergmann, D. C., Williams, C. M., \& Sozzani, R. (2019). Stem-cell-ubiquitous genes spatiotemporally coordinate division through regulation of stemcell-specific gene networks. Nat Commun, 10(5574). https://doi.org/https://doi.org/10.1038/s41467-019-13132-2

Clark, N. M., Fisher, A. P., Berckmans, B., Van den Broeck, L., Nelson, E. C., Nguyen, T. T., BustilloAvendaño, E., Zebell, S. G., Moreno-Risueno, M. A., Simon, R., Gallagher, K. L., \& Sozzani, R. (2020). Protein complex stoichiometry and expression dynamics of transcription factors modulate stem cell division. Proceedings of the National Academy of Sciences of the United States of America. https://doi.org/10.1073/pnas.2002166117

Clark, N. M., Hinde, E., Winter, C. M., Fisher, A. P., Crosti, G., Blilou, I., Gratton, E., Benfey, P. N., \& Sozzani, R. (2016). Tracking transcription factor mobility and interaction in Arabidopsis roots with fluorescence correlation spectroscopy. ELife, 5, 1-25. https://doi.org/10.7554/elife.14770

Clark, N. M., \& Sozzani, R. (2017). Measuring Protein Movement, Oligomerization State, and ProteinProtein Interaction in Arabidopsis Roots Using Scanning Fluorescence Correlation Spectroscopy (Scanning FCS) BT - Plant Genomics: Methods and Protocols (W. Busch (ed.); pp. 251-266). Springer New York. https://doi.org/10.1007/978-1-4939-7003-2_16

Clark, N. M., Van den Broeck, L., Guichard, M., Stager, A., Tanner, H. G., Blilou, I., Grossmann, G., IyerPascuzzi, A. S., Maizel, A., Sparks, E. E., \& Sozzani, R. (2020). Novel Imaging Modalities Shedding Light on Plant Biology: Start Small and Grow Big. Annual Review of Plant Biology, 71, 789-816. https://doi.org/10.1146/annurev-arplant-050718-100038

Cruz-Ramírez, A., Díaz-Triviño, S., Blilou, I., Grieneisen, V. A., Sozzani, R., Zamioudis, C., Miskolczi, P., Nieuwland, J., Benjamins, R., Dhonukshe, P., Caballero-Pérez, J., Horvath, B., Long, Y., Mähönen, A. P., Zhang, H., Xu, J., Murray, J. A. H., Benfey, P. N., Bako, L., ... Scheres, B. (2012). A bistable circuit involving SCARECROW-RETINOBLASTOMA integrates cues to inform asymmetric stem cell division. Cell, 150(5), 1002-1015. https://doi.org/10.1016/j.cell.2012.07.017 
bioRxiv preprint doi: https://doi.org/10.1101/2020.11.30.404426; this version posted December 1,2020 . The copyright holder for this preprint (which was not certified by peer review) is the author/funder, who has granted bioRxiv a license to display the preprint in perpetuity. It is made available under aCC-BY 4.0 International license.

Dinneny, J. R., \& Benfey, P. N. (2008). Plant stem cell niches: standing the test of time. Cell, 132(4), 553-557. https://doi.org/10.1016/j.cell.2008.02.001

Ercoli, M. F., Ferela, A., Debernardi, J. M., Perrone, A. P., Rodriguez, R. E., \& Palatnik, J. F. (2018). GIF Transcriptional Coregulators Control Root Meristem Homeostasis. The Plant Cell, 30(2), 347359. https://doi.org/10.1105/tpc.17.00856

Fisher, A. P., \& Sozzani, R. (2016). Uncovering the networks involved in stem cell maintenance and asymmetric cell division in the Arabidopsis root. Current Opinion in Plant Biology, 29, 38-43. https://doi.org/https://doi.org/10.1016/j.pbi.2015.11.002

Forzani, C., Aichinger, E., Sornay, E., Willemsen, V., Laux, T., Dewitte, W., \& Murray, J. A. H. (2014). WOX5 suppresses CYCLIN D activity to establish quiescence at the center of the root stem cell niche. Current Biology : CB, 24(16), 1939-1944. https://doi.org/10.1016/j.cub.2014.07.019

Gallagher, K. L., \& Benfey, P. N. (2009). Both the conserved GRAS domain and nuclear localization are required for SHORT-ROOT movement. The Plant Journal : For Cell and Molecular Biology, 57(5), 785-797. https://doi.org/10.1111/j.1365-313X.2008.03735.x

Heidstra, R., Welch, D., \& Scheres, B. (2004). Mosaic analyses using marked activation and deletion clones dissect Arabidopsis SCARECROW action in asymmetric cell division. Genes \& Development, 18(16), 1964-1969. https://doi.org/10.1101/gad.305504

Helariutta, Y., Fukaki, H., Wysocka-Diller, J., Nakajima, K., Jung, J., Sena, G., Hauser, M.-T., \& Benfey, P. N. (2000). The SHORT-ROOT Gene Controls Radial Patterning of the Arabidopsis Root through Radial Signaling. Cell, 101(5), 555-567. https://doi.org/https://doi.org/10.1016/S00928674(00)80865-X

Huynh-Thu, V. A., Irrthum, A., Wehenkel, L., \& Geurts, P. (2010). Inferring regulatory networks from expression data using tree-based methods. PloS One, 5(9), e12776. https://doi.org/10.1371/journal.pone.0012776

Koizumi, K., Hayashi, T., Wu, S., \& Gallagher, K. L. (2012). The SHORT-ROOT protein acts as a mobile, dose-dependent signal in patterning the ground tissue. Proceedings of the National Academy of Sciences, 109(32), 13010 LP - 13015. https://doi.org/10.1073/pnas.1205579109

Krouk, G., Mirowski, P., LeCun, Y., Shasha, D. E., \& Coruzzi, G. M. (2010). Predictive network modeling of the high-resolution dynamic plant transcriptome in response to nitrate. Genome Biol, 11(12), R123. https://doi.org/10.1186/gb-2010-11-12-r123

Li, S., Yamada, M., Han, X., Ohler, U., \& Benfey, P. N. (2016). High-Resolution Expression Map of the Arabidopsis Root Reveals Alternative Splicing and lincRNA Regulation. Developmental Cell, 39(4), 508-522. https://doi.org/10.1016/j.devcel.2016.10.012

Long, Y., Smet, W., Cruz-Ramírez, A., Castelijns, B., de Jonge, W., Mähönen, A. P., Bouchet, B. P., Perez, G. S., Akhmanova, A., Scheres, B., \& Blilou, I. (2015). Arabidopsis BIRD Zinc Finger Proteins Jointly Stabilize Tissue Boundaries by Confining the Cell Fate Regulator SHORT-ROOT and Contributing to Fate Specification. The Plant Cell, 27(4), 1185-1199. https://doi.org/10.1105/tpc.114.132407

Long, Y., Stahl, Y., Weidtkamp-Peters, S., Postma, M., Zhou, W., Goedhart, J., Sánchez-Pérez, M.-I., Gadella, T. W. J., Simon, R., Scheres, B., \& Blilou, I. (2017). In vivo FRET-FLIM reveals cell-typespecific protein interactions in Arabidopsis roots. Nature, 548, 97. https://doi.org/10.1038/nature23317

Nakajima, K., Sena, G., Nawy, T., \& Benfey, P. N. (2001). Intercellular movement of the putative transcription factor SHR in root patterning. Nature, 413(6853), 307-311. https://doi.org/10.1038/35095061 
Petricka, J. J., Winter, C. M., \& Benfey, P. N. (2012). Control of Arabidopsis Root Development. Annual Review of Plant Biology, 63(1), 563-590. https://doi.org/10.1146/annurev-arplant042811-105501

Pi, L., Aichinger, E., van der Graaff, E., Llavata-Peris, C. I., Weijers, D., Hennig, L., Groot, E., \& Laux, T. (2015). Organizer-Derived WOX5 Signal Maintains Root Columella Stem Cells through Chromatin-Mediated Repression of CDF4 Expression. Developmental Cell, 33(5), 576-588. https://doi.org/https://doi.org/10.1016/j.devcel.2015.04.024

Prusinkiewicz, P., Crawford, S., Smith, R. S., Ljung, K., Bennett, T., Ongaro, V., \& Leyser, O. (2009). Control of bud activation by an auxin transport switch. Proceedings of the National Academy of Sciences of the United States of America, 106(41), 17431-17436. https://doi.org/10.1073/pnas.0906696106

Radny, J., \& Meyer, K. M. (2018). The role of biotic factors during plant establishment in novel communities assessed with an agent-based simulation model. PeerJ, 6, e5342. https://doi.org/10.7717/peerj.5342

Saltelli, A., Annoni, P., Azzini, I., Campolongo, F., Ratto, M., \& Tarantola, S. (2010). Variance based sensitivity analysis of model output. Design and estimator for the total sensitivity index. Computer Physics Communications, 181(2), 259-270. https://doi.org/https://doi.org/10.1016/j.cpc.2009.09.018

Sarkar, A. K., Luijten, M., Miyashima, S., Lenhard, M., Hashimoto, T., Nakajima, K., Scheres, B., Heidstra, R., \& Laux, T. (2007). Conserved factors regulate signalling in Arabidopsis thaliana shoot and root stem cell organizers. Nature, 446(7137), 811-814. https://doi.org/10.1038/nature05703

Shannon, P., Markiel, A., Ozier, O., Baliga, N. S., Wang, J. T., Ramage, D., Amin, N., Schwikowski, B., \& Ideker, T. (2003). Cytoscape: a software environment for integrated models of biomolecular interaction networks. Genome Research, 13(11), 2498-2504. https://doi.org/10.1101/gr.1239303

Sobol', I. M. (2001). Global sensitivity indices for nonlinear mathematical models and their Monte Carlo estimates. Mathematics and Computers in Simulation, 55(1), 271-280. https://doi.org/https://doi.org/10.1016/S0378-4754(00)00270-6

Sozzani, R., Cui, H., Moreno-Risueno, M. A., Busch, W., Van Norman, J. M., Vernoux, T., Brady, S. M., Dewitte, W., Murray, J. A. H., \& Benfey, P. N. (2010). Spatiotemporal regulation of cell-cycle genes by SHORTROOT links patterning and growth. Nature, 466(7302), 128-132. https://doi.org/10.1038/nature09143

Spurney, R. J., Van den Broeck, L., Clark, N. M., Fisher, A. P., de Luis Balaguer, M. A., \& Sozzani, R. (2020). tuxnet: a simple interface to process RNA sequencing data and infer gene regulatory networks. The Plant Journal : For Cell and Molecular Biology, 101(3), 716-730. https://doi.org/10.1111/tpj.14558

Stahl, Y., Grabowski, S., Bleckmann, A., Kühnemuth, R., Weidtkamp-Peters, S., Pinto, K. G., Kirschner, G. K., Schmid, J. B., Wink, R. H., \& Hülsewede, A. (2013). Moderation of Arabidopsis root stemness by CLAVATA1 and ARABIDOPSIS CRINKLY4 receptor kinase complexes. Current Biology, 23(5), 362-371.

The MathWorks, I. (2019). SimBiology. https://nl.mathworks.com/products/simbiology.html

van den Berg, C., Willemsen, V., Hendriks, G., Weisbeek, P., \& Scheres, B. (1997). Short-range control of cell differentiation in the Arabidopsis root meristem. Nature, 390(6657), 287-289. https://doi.org/10.1038/36856

Van den Broeck, L., Gordon, M., Inzé, D., Williams, C., \& Sozzani, R. (2020). Gene Regulatory Network 
bioRxiv preprint doi: https://doi org/10.1101/20201130.404426; this version posted December 1,2020 . The copyright holder for this preprint (which was not certified by peer review) is the author/funder, who has granted bioRxiv a license to display the preprint in perpetuity. It is made available under aCC-BY 4.0 International license.

Inference: Connecting Plant Biology and Mathematical Modeling. Frontiers in Genetics, 11, 457. https://doi.org/10.3389/fgene.2020.00457

Vercruyssen, L., Verkest, A., Gonzalez, N., Heyndrickx, K. S., Eeckhout, D., Han, S.-K., Jégu, T., Archacki, R., Van Leene, J., Andriankaja, M., De Bodt, S., Abeel, T., Coppens, F., Dhondt, S., De Milde, L., Vermeersch, M., Maleux, K., Gevaert, K., Jerzmanowski, A., ... Inzé, D. (2014). ANGUSTIFOLIA3 binds to SWI/SNF chromatin remodeling complexes to regulate transcription during Arabidopsis leaf development. The Plant Cell, 26(1), 210-229. https://doi.org/10.1105/tpc.113.115907

Yao, C.-W., Hsu, B.-D., \& Chen, B.-S. (2011). Constructing gene regulatory networks for long term photosynthetic light acclimation in Arabidopsis thaliana. BMC Bioinformatics, 12(1), 335. https://doi.org/10.1186/1471-2105-12-335

Zhang, X., Zhou, W., Chen, Q., Fang, M., Zheng, S., Scheres, B., \& Li, C. (2018). Mediator subunit MED31 is required for radial patterning of \&lt;em\&gt;Arabidopsis\&lt;/em\&gt; roots. https://doi.org/10.1073/pnas.1800592115 